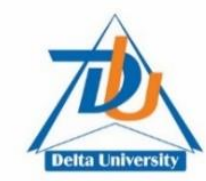

DE L T A U N I V ER S T Y SCIENTIFIC JOURNAL

Journal home page: www.deltauniv.edu.eg/dusj

\title{
MOLECULAR MECHANISMS AND SIGNALING PATHWAYS OF DIABETIC CARDIOMYOPATHY
}

\section{Mahmoud E. Youssef \\ Assistant lecturer of pharmacology and toxicology, department of pharmacology and biochemistry, Delta University for Science and Technology}

\begin{abstract}
Diabetes and heart failure incidence are increasing worldwide and responsible for high morbidity and mortality rates. The clinical outcomes arising from diabetic complications such as nephropathy, neuropathy, retinopathy and cardiomyopathy are more serious. This review focuses on diabetic cardiomyopathy clinical aspects and disease prognosis. Additionally, it focuses on the different molecular and protein signalling pathways involved in diabetic cardiomyopathy including the increased mitochondrial oxidative stress, AGE and RAGE pathways, activated RAAS, Impaired AMPK, alterations in PPARs, SGLT2 abnormalities, PKC activation MAPK and JNK alterations, activation of NF- $\mathrm{KB}$. targeting these pathways by different mechanisms could be promising in the management and prophylaxis against diabetic cardiomyopathy.
\end{abstract}

\section{List of abbreviations}

\begin{tabular}{|l|l|}
\hline AMP & Adenosine monophosphate \\
\hline HFpEF & heart failure with normal ejection fraction \\
\hline HFrEF & heart failure with reduced ejection fraction \\
\hline GLP-1 & glucagon-like peptide 1 \\
\hline GLUT-4 & glucose transporter type 4 \\
\hline eNOS & endothelium nitric oxidase enzyme \\
\hline NO & Nitric oxide \\
\hline IGF-1 & insulin-like growth factor 1 \\
\hline ERK1/2 & extracellular signal-regulated kinase 2 \\
\hline PI3K & phosphatidylinositol 3-kinase \\
\hline RAAS & renin angiotensin aldosterone system \\
\hline AGE & advanced glycation end products \\
\hline TGF-p1 & transforming growth factor beta 1 \\
\hline Akt & Protein kinase B \\
\hline
\end{tabular}

Delta University for Science and Technology

Coastal International Road, Mansoura, Gamasa City, Dakahlia, Egypt

E-mail: dusj@deltauniv.edu.eg

Journal homepage: www.deltauniv.edu.eg/dusj

page $\mid 87$ 


\begin{tabular}{|l|l|}
\hline IRS & Insulin receptor substrate \\
\hline ATP & Adenosine triphosphate \\
\hline mTOR & mammalian target of rapamycin \\
\hline FoxO1 & fork head box-containing protein, O \\
\hline NF-KB & nuclear factor kappa-light-chain-enhancer of activated B \\
\hline ROS & Reactive oxygen species \\
\hline FFA & Free fatty acids \\
\hline CD36 & cluster of differentiation 36 \\
\hline DAG & diacylglycerol \\
\hline PKC & protein kinase C \\
\hline CGI-58 & comparative gene identification 58 \\
\hline NADPH & nicotinamide adenine dinucleotide phosphate \\
\hline RAGE & Receptor of advanced glycation end products \\
\hline MAPK & mitogen-activated protein kinase \\
\hline JAK & Janus kinase \\
\hline TNF- $\boldsymbol{\alpha}$ & tumor necrosing factor- $\alpha$ \\
\hline IL & Interleukin \\
\hline NLRP3 & Interleukin 8 \\
\hline MCP-1 & monocyte chemotactic protein 1 \\
\hline TLR-4 & Tool lie receptor 4 \\
\hline NLRP3 & Cryopyrin \\
\hline Ag-II & Angiotensin II \\
\hline AT & Angiotensin II receptor \\
\hline MR & Mineralocorticoid receptor \\
\hline PERK & protein kinase RNA-like endoplasmic reticulum kinases \\
\hline Atg & autophagy related 1 \\
\hline Bcl-2 & B-cell lymphoma 2 \\
\hline EDHF & endothelium-derived hyperpolarizing factor \\
\hline ET-1 & endothelin-1 \\
\hline AMPK & AMP-activated protein kinase \\
\hline PPARs & peroxisome proliferators activated receptors \\
\hline SGLT1 & sodium glucose transporter-1 \\
\hline JNK & C-jun N-terminal kinase \\
\hline Nrf2 & nuclear factor erythroid-2- related factor 2 \\
\hline
\end{tabular}




\section{Overview:}

Because of diabetes, heart failure rate is increasing at an alarming rate leading to a high incidence of morbidity and mortality. For diabetic patients, the clinical outcomes arising from heart failure are more serious than non-diabetic patients. The presence of myocardial dysfunction in diabetic cases occurs in the absence of conventional cardiac risks such as coronary artery diseases, valvular diseases, hyperlipidemia and hypertension. This will lead to a specific descriptive terminology known as "diabetic cardiomyopathy".

Diabetic cardiomyopathy is mainly characterized by clinical heart failure that accompanied by cardiac fibrosis with systolic and diastolic dysfunction in addition to mitochondrial dysfunction, metabolic dysfunction, increased oxidative stress, reduced nitric oxide level, elevation in the collagen formation, impaired calcium flow, inflammation and activation of renin angiotensinaldosterone system. The possible Molecular mechanisms that linked to diabetic cardiomyopathy include abnormalities in adenosine monophosphate (AMP)-activated protein kinase, protein kinase $\mathrm{C}$, microRNA, O-linked-N-acetylglucosamine and exosome pathways.

In its early stages diabetic cardiomyopathy includes a hidden subclinical period characterized by structural and functional abnormalities, including left ventricular (LV) hypertrophy, fibrosis and cell signaling abnormalities. These pathophysiological changes of cardiac fibrosis and stiffness and associated subclinical diastolic dysfunction often evolve to heart failure with normal ejection fraction $(\mathrm{HFpEF})$ and eventual systolic dysfunction accompanied by heart failure with reduced ejection fraction (HFrEF).

\section{Clinical aspects of diabetic cardiomyopathy}

Epidemiological studies related to diabetes showed that the prevalence of heart failure in diabetic patients ranges from 19\% to 26\% (Ryden et al., 2000; Thrainsdottir et al., 2005). It was found that the incidence of heart failure was increased in both diabetic males and females which was found to be independent on obesity, hypertension, hyperlipidemia and coronary heart diseases (Kannel et al., 1974). Another study confirmed that the incidence of heart failure in diabetic patients (39\%) is higher than non-diabetic patients (23\%) (Aronow et al., 1999). Furthermore, it was observed that, there is a link between the increased level of glycated hemoglobin and the risk of heart failure where, an increase in the glycated hemoglobin level by $1 \%$ will lead to an increase in heart failure risk by $30 \%$ in type 1 diabetic patients and $8 \%$ in type II diabetic patients suggesting that hyperglycemia is promotor for heart failure (Lind et al., 2011).

Risk factors for diabetic cardiomyopathy are hyperglycemia, insulin resistance and impaired cardiac insulin metabolic signaling are major abnormalities in diabetes, and they are involved in the development of diabetic cardiomyopathy (Fig 1 and 2) (Jia et al., 2016). 


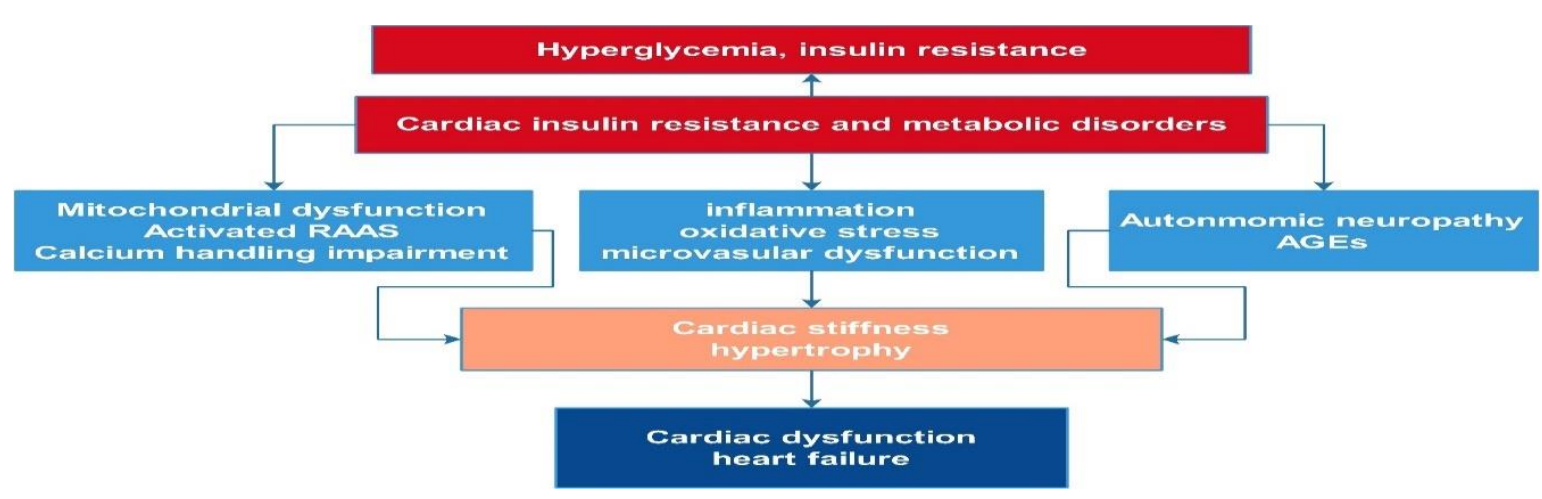

Fig. 1. Pathophysiological mechanisms of diabetic cardiomyopathy. Hyperglycemia, insulin resistance, and hyperinsulinemia induce cardiac insulin resistance and metabolic disorders that increase mitochondria dysfunction, oxidative stress, AGEs, impairment of mitochondria $\mathrm{Ca} 2+$ handling, inflammation, activation of RAAS, autonomic neuropathy, endoplasmic reticulum stress, cardiomyocyte death, as well as microvascular dysfunction. These pathophysiological abnormalities promote cardiac stiffness, hypertrophy, and fibrosis, resulting in cardiac diastolic dysfunction, systolic dysfunction, and heart failure. Abbreviations: AGEs, advanced glycation end-products; RAAS, renin-angiotensin-aldosterone system.

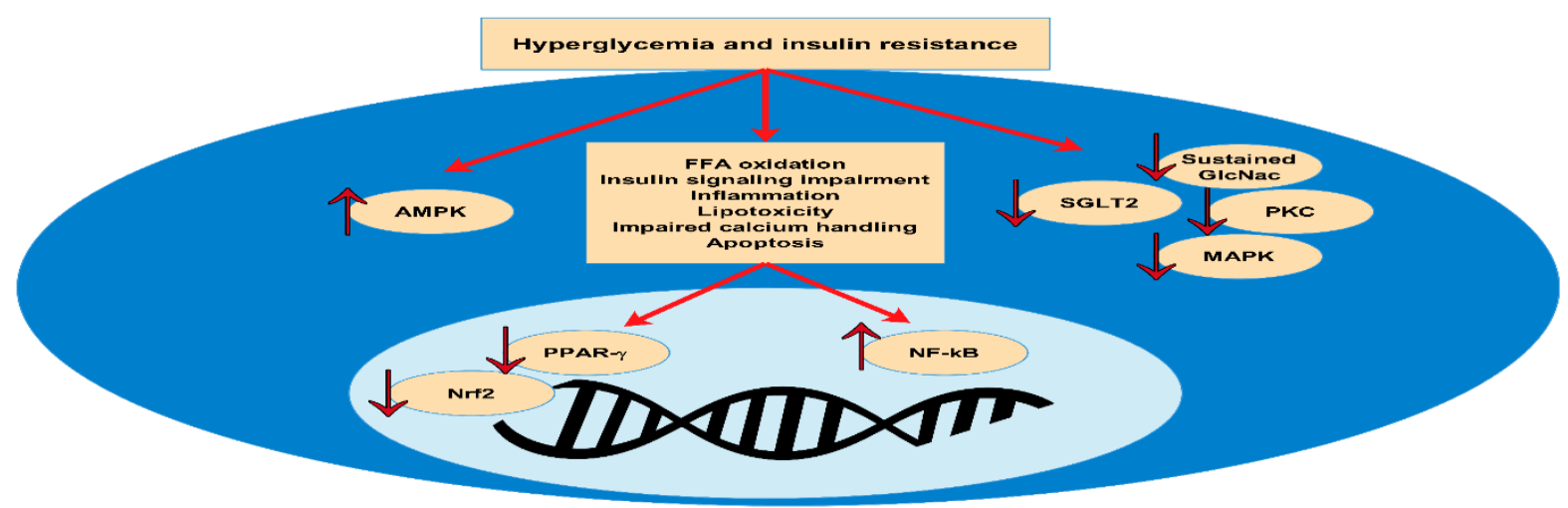

Fig. 2. The molecular proteins and signaling pathways in hyperglycemia- and insulin resistance diabetic cardiomyopathy. Increased PKC, MAPK, NF- $\kappa B$, SGLT2, O -GlcNAc and CREM signaling, dysregulation of miRNA and exosomes, and reduction of AMPK, PPAR- $\gamma$ and Nrf 2 induce cardiac insulin resistance, subcellular component abnormalities, metabolic disorders, and structural changes, resulting in diabetic cardiomyopathy. Abbreviations: AMPK, AMP-activated protein kinase; PPAR, peroxisome proliferator-activated receptor; Nrf2, nuclear factor erythroid 2-related factor 2; PKC, protein kinase C; MAPK, mitogen activated protein kinase; NF- $\kappa \mathrm{B}$, nuclear factor kappa-light-chain-enhancer of activated B cells; SGLT2, sodium-glucose cotransporter-2; O -GlcNAc, O -linked N-acetylglucosamine; CREM, cyclic adenosine 5'monophosphate-responsive element modulator; miRNA; microRNA 
3. Progression of diabetic cardiomyopathy to heart failure

Diabetic cardiomyopathy is asymptomatic in the early stages (Jia et al., 2016). The earliest manifestations are left ventricular hypertrophy that is associated left ventricular compliance that is characterized by dysfunction in early diastolic filling, increased atrial filling, and prolonged isovolumetric relaxation (Jia et al., 2016).The development of systolic dysfunction will lead to subsequent symptomatic heart failure.

The diastolic dysfunction that observed by magnetic resonance in rats showed its association with impaired cardiac metabolic signalling of insulin (Jia et al., 2015). The cardiac abnormality is believed to be due to cardiomyocytes stiffness, cardiac fibrosis and cardiac hypertrophy (Fig. 1). A study carried by The Cardiovascular Health showed that the ventricular septal wall and the left ventricular wall was greater in diabetic patients compared to non-diabetic which led to impairment in cardiac functions (M. Lee $e t$ al., 1997).

There is a remarkable epidemiological evidence that obesity, due to excessive carbohydrates intake and decreased exercise, is one of the most risk factors of diabetes and associated cardiac abnormalities. Changes in life style such as exercise, diet and weight control, smoking cessation and minimizing stress are efficacious approaches for the prophylaxis against diabetic cardiomyopathy. Sustained control of blood glucose level (BGL) reduces the chance of diabetic cardiomyopathy. A study carried by (Tate et al., 2017) proved that normalization of BGL by insulin therapy reduced cardiac collagen formation the diastolic dysfunction in type 1 diabetic model in rats. Additionally, in a retrospective study of 10920 patients with type II diabetes, metformin administration is associated with low mortality risk in diabetic patients (Andersson et al., 2010). Moreover, the beneficial effect on cardiovascular outcomes of glucagon-like peptide 1 (GLP-1) receptor agonist and sodium-glucose transporters was remarkable in type 2 diabetic patients (Jia et al., 2016). In contrast, it was found that peroxisome proliferator activated receptor agonists and dipeptidyl peptidase 4 inhibitors increased the risk of heart failure in type 2 diabetes. Finally, treatment with two long acting GLP1 receptor agonists significantly minimized the cardiovascular events and heart failure in high risk type 2 diabetic patients (MarsoBain et al., 2016; MarsoDaniels et al., 2016). These results suggest that the administration of these anti-diabetic drugs may have a role in lowering the risk of the development of cardiovascular disorders in type 2 diabetes.

\section{Functional phenotype of diabetic cardiomyopathy}

The first stage of diabetic cardiomyopathy is usually asymptomatic. It is characterized by an increase in collagen and fibrotic rates which lead to stiffness; a reduced early diastolic filling; arterial enlargement with increased early filling; elevated left ventricular end-diastolic pressure (Westermeier et al., 2016). Many factors are contributed in the development of diabetic 
cardiomyopathy including: hyperglycemia, increased free fatty acids level, cardiac insulin resistance, tissue inflammation, oxidative stress, activation of renin angiotensin-aldosterone system, sympathetic overstimulation, reduced activation of $\mathrm{Ca}^{++}$ (Fig.1) pump and insufficient sequestration of $\mathrm{Ca}^{++}$in endoplasmic reticulum (Talukder et al., 2008).

The second stage of diabetic cardiomyopathy is distinguished by left ventricular hypertrophy, advanced cardiac diastolic dysfunction, and the consequent appearance of clinical manifestations of heart failure (Jia et al., 2016). Along with the development of diabetic cardiomyopathy, diastolic dysfunction and reduced cardiac function may exist with systolic dysfunction which may lead to a reduction in ejection fraction, enlargement in the left ventricles, shortened ejection period, and increased filling pressure with increased resistance to filling (Jia et al., 2016). The mechanical defects in cardiac contraction is due to abnormalities in the expression of contractile and regulatory protein (Pollack et al., 1986). Troponin phosphorylation is believed to contribute in the depression myocardial contractility, since cardiomyocytes contraction could be regulated by myosin light chain- 2 and troponin I (Malhotra et al., 1997).

The underlying mechanisms involved in diabetic cardiomyopathy in type 2 diabetes was mainly investigated in $\mathrm{db} / \mathrm{db}$ mice, ob/ob mice, and diabetic patients (Jia et al., 2016). The impact of type 1 diabetes on systolic and diastolic function is less clear. However, diastolic dysfunction was often observed in type 1 diabetes as well as type 2 diabetes (Kanamori et al., 2015). In type diabetes the underlying mechanisms of cardiomyopathy are overlapped but in type 2 diabetes different molecular alterations are found (Holscher et al., 2016). For example, cardiac hypertrophy was not observed and systolic functions was preserved in type 1 diabetes of Akita mice compared to control animals (Bugger et al., 2008). The autophagy of cardiomyocytes was enhanced in type 1 diabetes while, it was suppressed in type 2 diabetes (Kanamori et al., 2015). Therefore, different studies were essential in order to understand the differences in phenotypes and the underlying mechanisms that are associated with diabetic cardiomyopathy in both type 1 and type 2 diabetes.

In conclusion, the cardiac dysfunction in diabetic patients starts from subclinical cardiac abnormalities such as left ventricular fibrosis to reach observable diastolic dysfunction and eventually a reduced ejection fraction due to systolic dysfunction. Many non-invasive techniques are sued to detect any changes in the cardiac structure and function including echocardiography, computed tomography, and magnetic resonance imaging (Jia et al., 2016). Moreover, other blood markers such as elevated levels of atrial natriuretic peptide and $\mathrm{O}$-linked $\mathrm{N}$-acetylglucosamine are important markers for the diagnosis of diabetic cardiomyopathy (Jia et al., 2016).

\section{Molecular mechanisms underlying} diabetic cardiomyopathy

Cardiac structural abnormalities 
The mechanism responsible for cardiomyocytes stiffness in the diabetic cardiomyopathy includes lowering of sarcoplasmic $\mathrm{Ca}++$ pump due to the decreased glucose transporter type 4 (GLUT4) activity with accompanied decrease in glucose uptake (Jia et al., 2016). Moreover, the abnormal insulin metabolic signalling will decrease insulin-mediated endothelium nitric oxidase enzyme (eNOS) activity which lead to a decrease in nitric oxide (NO) formation leading to an increase in intracellular $\mathrm{Ca}++$ with concurrent decrease in $\mathrm{Ca}$ uptake by sarcoplasmic reticulum (Jia et al., 2016). Additionally, the decrease in $\mathrm{NO}$ availability will decrease the phosphorylation of titin increasing the expression of stiff titin isoform $\mathrm{N} 2 \mathrm{~B} / \mathrm{N} 2 \mathrm{BA}$ which will increase the cardiac stiffness and impair the cardiac relaxation (Jia et al., 2016).

Other relevant abnormalities in diabetes include hyperglycemia, insulin resistance and oxidative stress. This will increase the expression cardiomyocyte hypertrophic genes including insulin-like growth factor 1 (IGF-1) receptor, and B type natriuretic peptide (Rosenkranz et al., 2003). Moreover, IGF-1 could promote cardiac hypertrophy through different signaling pathways such as extracellular signalregulated kinase 2 (Erk1/2) and phosphatidylinositol 3-kinase (PI3K) pathways (Sundgren et al., 2003).

The changes in cardiac architecture in diabetic cardiomyopathy include stiff collagen deposition, cardiac interstitial fibrosis, abolition of cardiac fibrils, perivascular fibrosis, thickened small coronary blood vessels and sclerosis of microvascular coronary blood vessels (Mytas et al., 2009; J. Wang et al., 2006). Activation of the renin angiotensin aldosterone system (RAAS) and advanced glycation end products (AGE)-mediated signaling in addition to hyperglycemia could lead to the activation of transforming growth factor beta 1 (TGF- $\beta 1$ ) pathway and extracellular matrix degradation (Bando et al., 2014). Many biomarkers could be clinically for diagnosis of cardiomyopathy such as inflammatory cytokines, connective tissue growth factors, galectin-3 and metalloproteinases (Passino et al., 2015). So, increased fibronectin level, collagen content in association with interstitial fibrosis are characteristic sign for diabetic cardiomyopathy that occur due to reduce $\mathrm{NO}$ availability, increased oxidative stress, impaired insulin metabolic signaling and elevated TGF- $\beta$ (Jia et al., 2015).

Cardiac insulin resistance and diabetic cardiomyopathy

Cardiac insulin signaling controls many cellular metabolic processes via controlling protein synthesis, glucose utilization, and cell survival. As in skeletal muscles and other body tissues, the glucose transport to the cardiac tissue is mediated by GLUT4. When insulin binds to its receptor, it activates insulin signaling/docking molecule insulin receptor substrate (IRS)-1/2 and subsequent stimulation of $\mathrm{PI} 3 \mathrm{~K} /$ protein kinase B (Akt) leading to stimulation of GLUT4 translocation to the cell membrane (Jia et al., 2016). Furthermore, myocardial insulin activity promotes eNOS activation and NO 
formation which is necessary for the optimal coronary microvascular blood flow and cardiac functions (Jia et al., 2016; Jia et al., 2015). Lack of insulin receptor in myocardium decreases the glucose uptake, which lead to an increase in cardiac reactive oxygen species (ROS) formation, which cause mitochondrial dysfunction (Bugger $e t$ al., 2012; Qi et al., 2013). Furthermore, adenosine triphosphate (ATP) content was reduced in IRS-1/2 knockout cardiomyocytes which impairs cardiac metabolism, that is accompanied with increased fibrosis and high incidence of cardiac failure (Bugger et al., 2012; Qi et al., 2013).

The E3 ubiquitin ligase, mitsugumin 53, may play an essential negative role in maintaining insulin signaling (Song et al., 2013). Elevated cardiac MG53 protein levels were linked to the increased degradation of insulin receptor. Additionally, the insulin signaling was diminished and fibrosis increased after overexpression of MG53 in cardiomyocytes (F. Liu et al., 2015) suggesting that decreasing cardiac levels of MG53 may be a potential therapeutic target in the prevention of diabetic cardiomyopathy and progression to heart failure.

The cardiac insulin metabolism can may be impaired by risk factors such as obesity and RAAS abnormalities. This occur through enhanced activation of mammalian target of rapamycin (mTOR) signaling pathway (Jia et al., 2016), which increases the phosphorylation of serine with reduced tyrosine phosphorylation of IRS-1/2 leading to ana impairment in PI3K engagement and Akt/eNOS induction. This will impair NO formation leading to further impairment in coronary blood vessels relaxation which will decrease the delivery of glucose to cardiac tissue (Jones et al., 2006; Vincent et al., 2004; Vincent et al., 2006; Vollus et al., 2007). Additionally, NO impairment will activate the collagen cross-linking promoting cardiac fibrosis and stiffness (Bertoni et al., 2006).

Tumor necrosing factor alpha (TNF$\alpha)$ is a pro-inflammatory cytokine, which was proved to promote cardiac insulin resistance through promoting the activation of nuclear factor kappa-light-chain-enhancer of activated $\mathrm{B}$ cells $(\mathrm{NF}-\mathrm{\kappa B})$ and c-Jun N terminal kinase (JNK). NF- $\mathrm{\kappa B}$ and JNK induce phosphorylation of IRS-1 (Jia et al., 2016). Activation of fork head boxcontaining protein, O subfamily (FoxO1) directly lead to insulin resistance through regulating IRS1 signaling and decreasing PI3K/Akt signaling (Battiprolu et al., 2012). Furthermore, heart failure was markedly decreased after deletion of cardiac FoxO1 in animals (Qi et al., 2015). Therefore, FoxO1 may provide an interesting therapeutic strategy for treating diabetic cardiomyopathy (Qi et al., 2015).

Decreased flexibility in substrate utilization in diabetic cardiomyopathy

In normal physiological conditions, the heart flexibly utilizes energy from various substrates including free fatty acids, glucose, lactate, ketone bodies and some amino acids. This essential for the production of ATP as a source of energy essential for normal cardiac function (Jia et al., 2016). About 95\% of ATP 
is produced by oxidative phosphorylation in the mitochondria of cardiac cell, whereas, the remaining $5 \%$ of the remaining ATP is formed glucose or lactate in cardiac tissue (Guo et al., 2017). Mitochondrial volume represents about 20-30\% of cardiomyocytes total volume (Jia et al., 2016). The insulin resistance reduces the cardiac ability for glucose uptake leading to switching to the free fatty acids utilization (Guo et al., 2017). As a result, the oxidative phosphorylation is impaired and the production of reactive oxygen species (ROS) is increased. Due to the limited anti-oxidant capacity in the cardiac tissue, this will lead to the destruction of $\mathrm{NO}$ and reducing the its bioavailability (MarsoBain et al., 2016).

The role of abnormal FFA metabolism in diabetic cardiomyopathy

The diabetic cardiomyopathy is also increased by the concurrent increase in free fatty acids (FFA) released form adipose tissue and the elevated free fatty acids capacity of myocytes sarcolemma (Guo et al., 2017). The free fatty acids uptake is promoted by the cluster of differentiation 36 (CD36) which is a protein that located in the cell membrane of myocytes and believed to be abundant in diabetic cardiomyopathy (T. W. Lee et al., 2017). This will lead to an elevation in the free fatty acids uptake rate in diabetics' heart (T. W. Lee et al., 2017). Additionally, CD36 is participated in adenosine monophosphate activated (AMPK) role in cardiomyocytes uptake of free fatty acids. That was proved in CD36kockout mice, where, the uptake of free fatty acids was reduced by $70 \%$ in their hearts
(Habets et al., 2007). AMPK activation seems to be responsible for glucose uptake and glycolysis in diabetic cardiomyocytes (Zou et al., 2013). However, its activation will lead to an accompanied increase in the free fatty acids uptake and accumulation of triglycerides which in turn reduces the glucose utilization that is common in diabetic cardiomyopathy (Finck et al., 2002).

The diabetic cardiomyopathy is aggravated by many lipid metabolites such as diacylglycerol (DAG) that impair the insulin signaling mechanisms. In obese, the decrease in insulin sensitivity is believed to be associated with elevated DAG and increased protein kinase $\mathrm{C}$ (PKC) activity. The endoplasmic reticulum stress is increased by DAG (Samuel et al., 2016). Moreover, increased DAG will lower the formation of NO (Atkinson et al., 2003).

The triglycerides metabolism by lipase enzyme is regulated by a lipid dropletassociated protein known as comparative gene identification 58 (CGI-58) (Cantley et al., 2013). The knockout of CGI-58 gene prevented the accumulation of DAG at plasma membrane in addition to inhibiting PKC activity (Jornayvaz et al., 2011).

Meanwhile, another lipid metabolite known as ceramide can activate PKC leading to subsequent inhibition of insulin metabolic Akt/PKB signaling, emaciating the translocation of GLUT4 and insulin mediated glucose uptake by diabetic cardiomyocytes (Atkinson et al., 2003).

Delta University for Science and Technology

Coastal International Road, Mansoura, Gamasa City, Dakahlia, Egypt

E-mail: dusj@deltauniv.edu.eg

Journal homepage: www.deltauniv.edu.eg/dusj

page $\mid 95$ 
Mitochondrial dysfunction in the genesis of diabetic cardiomyopathy

The mitochondrial dysfunction could be involved in the development of cardiomyopathy and heart failure in diabetics (Kim et al., 2008). Over $90 \%$ of ATP is formed by mitochondrial oxidative phosphorylation in cardiomyocytes, but, in diabetics the production of ATP is switched from glucose utilization into free fatty acids utilization by mitochondria (Jia et al., 2016). This will lead to subsequent elevation in the generation of ROS due to impaired oxidative phosphorylation. Furthermore, cell death is promoted by respiratory dysfunction in mitochondria due to changed mitochondrial $\mathrm{Ca}^{++}$handling (Anderson et al., 2009). Cardiomyocytes autophagy and cardiac cell death may occur due to increased $\mathrm{Ca}^{++}$ overload induced by metabolic stress that lead to excessive opening of mitochondrial transition pores (Anderson et al., 2011).

Mitochondrial oxidative stress in the pathogenesis of diabetic cardiomyopathy.

Cardiac insulin resistance and its progression to cardiomyopathy is promoted by oxidative stress. Mitochondrial oxygen metabolism at complex I and II within electron transport chain usually results in the formation of several byproducts such as ROS (Jia et al., 2016). Under normal physiological conditions, the major electrochemical proton gradient is used for synthetization of ATP (Jia et al., 2016).

Insulin resistance and hyperglycemia activate the influx of NADH into the respiratory chain of mitochondria which may result in the hyperpolarization of the inner membrane of mitochondria, electron transport inhibition in complex III and excessive production of ROS (Teshima et al., 2014). Another source of ROS in cardiac tissue is the nicotinamide adenine dinucleotide phosphate (NADPH). The increased activity of NADPH oxidase was previously recorded in cardiac insulin resistance and obesity (Jia et al., 2018). Additionally, the cardiac fibrosis could be enhanced by RAAS-mediated NADPH oxidase activity through activating TGF- $\beta 1$ Smad 2/3 pathway (S. J. Lee et al., 2009; Murdoch et al., 2014).

Increasing the activity of xanthine oxidase and microsomal P-450 activity is considered and important source of ROS in diabetic cardiomyopathy. They are involved in several mechanisms including the elevated expression of AGEs receptor, increased PKC signalling and the inhibition of eNOS and prostacyclin synthase activity (Giacco et al., 2010).

Role of AGEs and RAGE in the pathophysiology of diabetic cardiomyopathy

Hyperglycemia is contributed in the accumulation of AGEs and the subsequent alteration in the myocardial structure. This occurs due to several mechanisms such as lips and protein oxidation, nonenzymatic glycation, production of myocardial collagen and fibronectin in addition to cross-linking of connective tissue and fibrosis (Jia et al., 2016). The AGE-induced cross-linking of connective tissue of extracellular matrix stimulates the fibrotic process leading to 
impaired passive relaxation (Jia et al., 2016). Moreover, AGEs may promote cardiac structural changes and alter the energetics of myocardium through binding to Receptor of advanced glycation end products (RAGE) (Jia et al., 2016). This reaction stimulates the formation of pro-inflammatory responses and the production of connective tissue which is mediated by mitogen-activated protein kinase (MAPK) and Janus kinase (JAK) pathways (Jia et al., 2016). Also, as mentioned before, the AGEs may elevate the production of ROS and TGF- $\beta 1$-Smad $2 / 3$ pathway activation which will lead to fibrosis and production of connective tissue.

Impaired mitochondrial $\mathrm{Ca} 2+$ handling in diabetic cardiomyopathy

The cytosolic $\mathrm{Ca}^{++}$regulates several physiological and biochemical functions including regulation of cellular metabolism, muscle contraction and cell signalling. In cardiac contraction, the $\mathrm{Ca}^{++}$reaches the cytoplasm through L-type voltage sensitive channels of sarcolemma after depolarization. This will trigger the release of $\mathrm{Ca}^{++}$from the sarcoplasmic reticulum which binds to troponin $\mathrm{C}$ protein and induce the contraction of myofibrils (Kanaporis et al., 2017; W. Liu et al., 2017). During cardiac relaxation, $\mathrm{Ca}^{++}$ is re-uptaken by sarcoplasmic reticulum while the remaining of $\mathrm{Ca}^{++}$is pumped out actively by the aid of $\mathrm{Na}^{+} / \mathrm{Ca}^{++}$exchanger or by $\mathrm{Ca}^{++}$pumps in the plasma membrane (Kanaporis et al., 2017). In diabetic cardiomyopathy, the handling of $\mathrm{Ca}^{++}$ transport by $\mathrm{Ca}^{++}$membrane pump and the $\mathrm{Na}^{+} / \mathrm{Ca}^{++}$exchanger is impaired which may lead to the prolongation of diastolic relaxation (Jia et al., 2016). Additionally, the accumulation of intracellular $\mathrm{Ca}^{++}$will prolong the decay of intracellular $\mathrm{Ca}^{++}$, slow the $\mathrm{Ca}^{++}$transients and impair the uptake of $\mathrm{Ca}^{++}$by the sarcoplasmic reticulum (Belke $e t$ al., 2004; Ye et al., 2004).

Inflammation as an instigator of diabetic cardiomyopathy

A maladaptive inflammatory response was indicated in diabetic cardiomyopathy development. This process involves many inflammatory cells including mast cells, dendritic cells, macrophages, eosinophils and neutrophils (Jia et al., 2016). The expression of several inflammatory mediators such as tumor necrosing factor- $\alpha$ (TNF- $\alpha$ ), interlukin-6 (IL-6), interlukin-8 (IL-8), vascular cell adhesion molecule and monocyte chemotactic protein 1 (MCP-1) was proved to increase in diabetic cardiomyopathy. All these inflammatory mediators may participate in oxidative stress and cardiac fibrosis which is associated with diastolic dysfunction (Jia et al., 2016). Toll like receptor 4 (TLR-4) have a role in increasing the expression of these cytokines and innate immune responses through triggering NF- $\mathrm{KB}$ activity (Uchimura $e t$ al., 2014). This inflammatory response could occur in different cardiac cells including endothelial coronary cells, fibroblasts and cardiomyocytes.

The NLRP3 inflammasome could be activated due to impaired insulin metabolic signalling which is associated with activation of procaspase-1 (Pal et al., 2017). the activated caspase-1 along with other 
cytokines such as IL-1 $\beta$ and IL-18 may enhance other inflammatory pathways involving ROS, chemokines and NF- $\mathrm{kB}$. the increased ROS and coronary monocytes/macrophages migration will enhance the polarization of these inflammatory cells into proinflammatory M1 phenotypes. This was proves by many studies which stated that in diabetic cardiomyopathy the level of proinflammatory M1 phenotype was elevated while the antiinflammatory M2 phenotype was depressed (Jia et al., 2015).

Activated RAAS in the genesis of diabetic cardiomyopathy

Due to hyperglycemia and insulin resistance, the activation of systemic and tissue RAAS is increased which play an important role in diabetic cardiomyopathy and myocardial fibrosis (Jia et al., 2015). There is a correlation between serum levels of angiotensin II (Ag-II) and plasma glucose level in insulin resistance (Xu et al., 2013). Additionally, the expression of the proinflammatory Ag-II receptor 1 (AT-1) is increased while the expression of the antiinflammatory Ag-II receptor 2 (AT-2) is repressed in diabetics (Giacchetti et al., 2005). Many studies prove that insulin resistance, the activated RAAS play a role in diabetic cardiomyopathy through increasing mineralocorticoids systemic level with concurrent overexpression of tissue mineralocorticoid receptor (MR) (Baudrand et al., 2016; Miller, 1999; Miller et al., 1996). The inhibition of MR signalling pathway minimizes mortality and morbidity in diabetic patients. Moreover, RAAS stimulation could activate mTOR/S6K1 signalling which may have a role in systemic and cardiac insulin resistance induction (Kim et al., 2012).

Endoplasmic reticulum stress and increased cell death in diabetic cardiomyopathy

The myocardial endoplasmic reticulum function and stress is impaired in diabetic cardiomyopathy due to oxidative stress, release of proinflammatory mediators, lipotoxicity and the cumulation of misfolded proteins (Jia et al., 2016). Meanwhile, increased levels of unfolded protein and their degradation inhibits the protein synthesis and stimulate apoptotic processes and autophagy (Jia et al., 2016) which is a main risk factor in developing cardiac myopathy. In diabetic cardiomyopathy, the autophagy that is induced by endoplasmic stress is controlled by several pathways including $\mathrm{Ca}^{++}$dependent pathway, protein kinase RNA-like endoplasmic reticulum kinases (PERK) pathway, AMPK, mTOR and silent information regulator (sirt) pathways (Jia et al., 2016).

mTORC1 has been found to regulate autophagy by depressing the autophagy related 1 (Atg1)-Atg13-Atg101/FIP200 (FAK family interacting protein of $200 \mathrm{kDa}$ ) complex. Thus, the initiation of autophagy process is facilitated by inhibition of mTORC1 (L. Yang et al., 2015). The inositol requiring enzyme 1 arm of ER stress results in the activation of JNK and elevated phosphorylation of B-cell lymphoma (Bcl-2), which encourages its dissociation from Beclin-1 (L. Yang et al., 2015). Thus, enhanced mTOR may serve as a meeting 
point for abnormalities involving the relationship between endoplasmic reticulum stress and autophagy in diabetic cardiomyopathy. However, in diabetic cardiomyopathy, dysregulation of autophagy impairs cardiomyocyte auto-phagosome and lysosome fusion (Xie et al., 2011). One study confirmed that treatment with metformin could increase AMPK activity with restoring autophagic activity, and inhibiting cardiomyocyte apoptosis. This may be performed by interfering with the Bcl-2 and Beclin1 complex in diabetic cardiac tissue (Xie et al., 2011).

Microvascular dysfunction in diabetic cardiomyopathy

Diabetic cardiomyopathy is defined as a cardiomyopathy that occur in the absence of notable coronary artery disease. however, diabetic cardiomyopathy could be accompanied with coronary vascular abnormalities that may affect the coronary blood flow. Decreasing coronary supply and myocardial perfusion will result in impairing the ventricular function which leads to subsequent clinical outcomes (Sandesara et al., 2018). The administration of MR antagonist minimized the occurrence of any cardiovascular disease in patients with type II diabetes through improving the coronary blood flow (Garg et al., 2015). Several structural and functional abnormalities in coronary blood vessels may occur in diabetics; luminal obstruction, infiltration of inflammatory cells and vascular fibrosis as structural changes while functional changes include dysfunction endothelial cells dysfunction, impaired vasorelaxation and vasoconstriction, diminished cardiac perfusion (Shome et al., 2017). The endothelial cells of the coronary blood vessels secrete several vasoactive substances such as NO, prostacyclin, endotheliumderived hyperpolarizing factor (EDHF). These factors play an essential vasodilator role (Vincent et al., 2004). In early stages of diabetes, the NO-induced vasodilation is impaired but the normal vascular function is preserved due to enhanced EDHF activity (Vincent et al., 2004). However, the activity of both factors is affected at last stages leading to significant vascular dysfunction (Vincent et al., 2004). High plasma concentration of endothelin-1 (ET-1) was recorded with concurrent diminution in eNOS production in diabetic cardiomyopathy (Widyantoro et al., 2010).

Impaired AMPK activation in diabetic cardiomyopathy

The AMP-activated protein kinase (AMPK) is an essential regulator of cellular homeostasis (Jia et al., 2016). The translocation of GLUT4 and expression is enhanced by cellular stress and elevated AMP/ATP ratio. This will increase the biogenesis of mitochondria leading to FFA oxidation and glycolysis (Zou et al., 2013). The activation of AMPK elevates the glucose uptake and reduce mTOR signalling and the synthesis of lipids and proteins (Abdel Malik et al., 2017). Therefore, enhancing the AMPK activity prevents the progression of diabetic cardiomyopathy. For this reason, AMPK is considered as a promising target for the treatment and prevention of diabetic cardiomyopathy. 
Alterations in activation of cardiac PPARs

The peroxisome proliferators activated receptors (PPARs) are expressed in different isoforms $(\alpha, \beta / \delta$ and $\gamma)$. They play a key role in lipid metabolism and energy hemostasis. Additionally, they exert different roles related to metabolism such as oxidative stress and inflammation (Jia et al., 2016). PPAR- $\alpha$ is highly expressed in the cardiac tissue and its activation affects FFA uptake their oxidation (Jia et al., 2016). PPAR- $\alpha$ is essential in regulating the assembly of lipoprotein and regulates oxidant and antioxidant defenses (T. I. Lee et al., 2013). the increased activity of cardiac PPAR- $\alpha$ decreases the $\mathrm{Ca}++$ uptake by sarcoplasmic reticulum which may lead to left ventricular hypertrophy, systolic dysfunction and elevated expression of B-type atrial natriuretic peptide (Finck et al., 2002).

Conversely, deletion of cardiac PPAR- $\alpha$ prevents fasting-induced expression of FFA metabolic genes and induces a switch from FFA to glucose utilization (Leone et al., 1999). The expression of PPAR- $\alpha$ is reduced in diabetic cardiomyopathy due to extensive exposure to elevated FFA. This will lead to a decrease in the FFA oxidation and accumulation of fats which may cause further depression in cardiac functions (Young et al., 2001; Zhou et al., 2000). However, studies performed on human type-II diabetic patients showed no significant alteration in PPAR- $\alpha$ expression (Razeghi et al., 2002). Further, diminution in PPAR- $\alpha$ in advanced disease may have maladaptive significances in standings of cardiac metabolism, including glucotoxicity and abnormalities in cardiac functions.

The role of PPAR- $\alpha$ in cardiac dysfunction development in diabetes has been insufficiently evaluated and needs further investigations. Similarly, PPAR- $\beta / \delta$ isoforms are expressed in cardiac tissue and regulate the expression of transcriptional gene and the metabolism of FFA (Cheng et al., 2004). Enhanced PPAR- $\beta / \delta$ signaling encourages the FFA utilization where, the deletion of PPAR- $\beta / \delta$ reduces the expression of FFA oxidative gene and FFA oxidation (Cheng et $a l ., 2004)$. Additionally, PPAR- $\gamma$ has an antihypertrophic and antiinflammatory roles in heart (Jia et al., 2016). Activation of PPAR- $\gamma$ enhances the glucose uptake by cardiac tissue and improves the cardiomyocyte insulin sensitivity (Jia et al., 2016). Thus, PPAR- $\gamma$ may be beneficial in maintaining glucose and FFA metabolism and cardiac function.

SGLT2 abnormalities and potential cardiac benefits of inhibition of this transporter

Glucose is actively absorbed from the gastrointestinal lumen into its epithelium primarily by sodium glucose transporter-1 (SGLT1), which is highly expressed in the membrane of enterocytes (Lehrke et al., 2017; Pham et al., 2017). In case of hyperglycemia and insulin resistance, the increased expression of SGLT1 and glucose transporters (GLUT1, GLUT2 and GLUT5) in addition to increased activity of sucrase, maltase and lactase, will increase the absorption of glucose and fructose through the intestinal mucosa (Lehrke et al., 2017; Pham et al., 2017). SGLT2 is primarily

Delta University for Science and Technology

Coastal International Road, Mansoura, Gamasa City, Dakahlia, Egypt

E-mail: dusj@deltauniv.edu.eg

Journal homepage: www.deltauniv.edu.eg/dusj

page $\mid 100$ 
expressed in the epithelial membrane of S1 segment of the proximal convoluted tubules in the kidneys (Lehrke et al., 2017; Pham et al., 2017). In diabetes, the expression of SGLT2 is markedly elevated in both humans, mice and rats (Sabolic et al., 2012; von Lewinski et al., 2010) which is related to the elevated BGL, increased glomerular filtration and reabsorption (Lytvyn et al., 2017). Conversely, the inhibition of SGLT2 leads to osmotic diuresis with increased sodium loss which lead to water loss and reduced blood pressure. All these mechanisms may alleviate diabetic cardiomyopathy and heart failure. Furthermore, treatment with SGLT2 inhibitors could shift the cellular metabolism from glucose to free fatty acids oxidation. This will increase the formation of ketone body, $\beta$-hydroxybutyrate, which is and efficient energy source for cardiac metabolism (Zinman et al., 2015).

PKC activation promotes development of diabetic cardiomyopathy

Protein kinase $\mathrm{C}$ signaling pathways are activated in diabetic cardiomyopathy due to hyperglycemia and insulin resistance. Furthermore, the PKC activity is promoted by inflammation, oxidative stress and enhanced RAAS activity. The PKC is found in different isoforms where, approximately fifteen isoforms where discovered in humans. These isoforms can be classified into 3 major subfamilies based on their signaling pathway and their mode of activation (Li et al., 2014). The main PKC isoform found to be involved in the development of diabetic cardiomyopathy are $\mathrm{PKC} \alpha, \mathrm{PKC} \beta, \mathrm{PKC} \varepsilon$, PKC $\theta$, and PKC $\delta$ (Li et al., 2014). For example, PKC $\beta 2$ was discovered to control hyperglycemia-induced cardiomyopathy in diabetic rats through alterations in insulin metabolic Akt/eNOS signaling pathway (Lei et al., 2013). moreover, the cardiac hypertrophy and fibrosis was reported to be improved in transgenic mouse model of diabetic cardiomyopathy subjected to targeted inhibition of PKC $\beta 2$ (Wakasaki et al., 1997).

Role of MAPK and JNK activation in the genesis of diabetic cardiomyopathy

The activation of MAPK activation was found to be involved in the pathogenesis of diabetic cardiomyopathy and heart failure. There are three major MAPK subfamilies that regulate cardiac growth and remodeling (Jia et al., 2016). These subfamilies are Erk1/2, p38 MAPK and JNKs. In streptozotocin-insulted diabetic models, the phosphorylation and activation of Erk 1/2 and p38 was elevated (Strniskova et al., 2003). Moreover, it was demonstrated that insulin resistance-induced cardiac abnormalities were associated with increased Erk 1/2 signalling (H. Zhang et al., 2001). Cjun $\mathrm{N}$-terminal kinase $(\mathrm{JNK})$ is mainly activated by inflammatory cytokine and oxidative stress which is contributed to endoplasmic reticulum stress and cardiac fibrosis. In contrast, the inhibition of JNK activation prevented the cardiac inflammation and apoptosis in diabetics (Y. Wang et al., 2014). JNK activation was reported to increase the cardiomyocyte apoptosis within a week in rodent diabetic model (Gurusamy et al., 2004). 
Role of NF- $\mathrm{KB}$ activation in the genesis of diabetic cardiomyopathy

The NF- $\mathrm{kB}$ is a major transcription factors that control proinflammatory cytokines expression and cell survival (J. Yang et al., 2009) thus, it is contributed to cardiac dysfunction in diabetic hearts. In nonstimulated cells, the NF- $\mathrm{kB}$ was found in cytoplasm however, after stimulation, IKB is phosphorylated and p50/p60 subunits are translocated to nucleus and bind with the $\mathrm{\kappa B}$ (J. Yang et al., 2009). in diabetes, the NF- $\mathrm{kB}$ is activated by several factors such as ROS, AGEs and activated cardiac tissue RAAS which will result in subsequent maladaptive immune responses and the release of proinflammatory cytokines such as IL-6 and TNFa (Jia et al., 2016).

Activated NF-KB in diabetic heart was associated with increased generation of ROS due to increased NADPH oxidase activity (Mariappan et al., 2010) which lead to reduction in NO bioavailability. Inhibition of NF- $\kappa B$ with pyrrolidine dithiocarbamate was shown to improve structural integrity of mitochondria and prevent the oxidative stress, leading to an increase in ATP synthesis and NO bioavailability which, restores cardiac function in diabetic animals (Mariappan et al., 2010).

\section{Abnormalities of Nrf2 related antioxidant actions in diabetic cardiomyopathy}

The nuclear factor erythroid-2- related factor 2 (Nrf2) is a leucine zipper protein that stimulate the expression of antioxidant proteins such as $\mathrm{HO}-1$ in response to oxidative stress (Fig 2). Nrf2 is regulated by keap1 as an inhibitor that targets Nrf2 for degradation thus reducing the levels of Nrf2 (Niture et al., 2014). Under oxidative stress, Nrf2 and its regulators are subjected to different modifications that cause Nrf2 dissociation from Keap1.

Free Nrf2 can then bind to small Maf proteins transcription factors in the nucleus to initiate the transcription process (Niture et al., 2014). Hyperglycemia and insulin resistance suppress the expression of $\mathrm{Nrf} 2$ and its activity through an Erk 1/2 mediated pathway in cardiomyocytes (Tan et al., 2011). Restoration of Nrf2 activity prevents diabetes-associated complications such as inflammatory reactions, fibrosis, and cardiac dysfunction (Z. Zhang et al., 2014). This could provide a potential strategy for the prophylaxis against diabetic cardiomyopathy.

\section{References}

1- Abdel Malik, R., Zippel, N., Fromel, T., Heidler, J., Zukunft, S., Walzog, B., . . . Fleming, I. (2017). AMPActivated Protein Kinase alpha2 in Neutrophils Regulates Vascular Repair via Hypoxia-Inducible Factor1alpha and a Network of Proteins Affecting Metabolism and Apoptosis. Circ Res, 120(1), 99-109. doi: 10.1161/CIRCRESAHA.116.309937

2- Anderson, E. J., Kypson, A. P., Rodriguez, E., Anderson, C. A., Lehr, E. J., \& Neufer, P. D. (2009). Substrate-specific derangements in mitochondrial metabolism and redox 
balance in the atrium of the type 2 diabetic human heart. J Am Coll Cardiol, 54(20), 1891-1898. doi: 10.1016/j.jacc.2009.07.031

3- Anderson, E. J., Rodriguez, E., Anderson, C. A., Thayne, K., Chitwood, W. R., \& Kypson, A. P. (2011). Increased propensity for cell death in diabetic human heart is mediated by mitochondrialdependent pathways. Am J Physiol Heart Circ Physiol, 300(1), H118124. doi:

10.1152/ajpheart.00932.2010

4- Andersson, C., Olesen, J. B., Hansen, P. R., Weeke, P., Norgaard, M. L., Jorgensen, C. H., . . . Gislason, G. H. (2010). Metformin treatment is associated with a low risk of mortality in diabetic patients with heart failure: a retrospective nationwide cohort study. Diabetologia, 53(12), 25462553. doi: 10.1007/s00125-0101906-6

5- Aronow, W. S., \& Ahn, C. (1999). Incidence of heart failure in 2,737 older persons with and without diabetes mellitus. Chest, 115(3), 867868. doi: 10.1378/chest.115.3.867

6- Atkinson, L. L., Kozak, R., Kelly, S. E., Onay Besikci, A., Russell, J. C., \& Lopaschuk, G. D. (2003). Potential mechanisms and consequences of cardiac triacylglycerol accumulation in insulin-resistant rats. Am J Physiol Endocrinol Metab, 284(5), E923-930. doi: 10.1152/ajpendo.00360.2002

7- Bando, Y. K., \& Murohara, T. (2014). Diabetes-related heart failure. Circ J,
78(3), 576-583. doi: 10.1253/circj.cj13-1564

8- Battiprolu, P. K., Hojayev, B., Jiang, N., Wang, Z. V., Luo, X., Iglewski, M., . . . Hill, J. A. (2012). Metabolic stress-induced activation of FoxO1 triggers diabetic cardiomyopathy in mice. J Clin Invest, 122(3), 11091118. doi: 10.1172/JCI60329

9- Baudrand, R., Gupta, N., Garza, A. E., Vaidya, A., Leopold, J. A., Hopkins, P. N., . . . Pojoga, L. H. (2016). Caveolin 1 Modulates Aldosterone-Mediated Pathways of Glucose and Lipid Homeostasis. J Am Heart Assoc, 5(10). doi: 10.1161/JAHA. 116.003845

10- Belke, D. D., Swanson, E. A., \& Dillmann, W. H. (2004). Decreased sarcoplasmic reticulum activity and contractility in diabetic $\mathrm{db} / \mathrm{db}$ mouse heart. Diabetes, 53(12), 3201-3208. doi: 10.2337/diabetes.53.12.3201

11- Bertoni， A. G., Goff, D. C., Jr., D'Agostino, R. B., Jr., Liu, K., Hundley, W. G., Lima, J. A., . . . Siscovick, D. S. (2006). Diabetic cardiomyopathy and subclinical cardiovascular disease: the MultiEthnic Study of Atherosclerosis (MESA). Diabetes Care, 29(3), 588594.

doi: 10.2337/diacare.29.03.06.dc05-1501

12-Bugger, H., Boudina, S., Hu, X. X., Tuinei, J., Zaha, V. G., Theobald, H. A., . . . Abel, E. D. (2008). Type 1 diabetic akita mouse hearts are insulin sensitive but manifest structurally abnormal mitochondria that remain coupled despite increased uncoupling

Delta University for Science and Technology

Coastal International Road, Mansoura, Gamasa City, Dakahlia, Egypt

E-mail: dusj@deltauniv.edu.eg

Journal homepage: www.deltauniv.edu.eg/dusj

page $\mid 103$ 
protein 3. Diabetes, 57(11), 29242932. doi: $10.2337 / \mathrm{db} 08-0079$

13-Bugger, H., Riehle, C., Jaishy, B., Wende, A. R., Tuinei, J., Chen, D., . . . Abel, E. D. (2012). Genetic loss of insulin receptors worsens cardiac efficiency in diabetes. J Mol Cell Cardiol, 52(5), 1019-1026. doi: 10.1016/j.yjmcc.2012.02.001

14-Cantley, J. L., Yoshimura, T., Camporez, J. P., Zhang, D., Jornayvaz, F. R., Kumashiro, N., . . . Shulman, G. I. (2013). CGI-58 knockdown sequesters diacylglycerols in lipid droplets/ERpreventing diacylglycerol-mediated hepatic insulin resistance. Proc Natl Acad Sci U S A, 110(5), 1869-1874. doi: 10.1073/pnas.1219456110

15-Cheng, L., Ding, G., Qin, Q., Huang, Y., Lewis, W., He, N., . . Y Yang, Q. (2004). Cardiomyocyte-restricted peroxisome proliferator-activated receptor-delta deletion perturbs myocardial fatty acid oxidation and leads to cardiomyopathy. Nat Med, 10(11), 1245-1250. doi: $10.1038 / \mathrm{nm} 1116$

16- Finck, B. N., Lehman, J. J., Leone, T. C., Welch, M. J., Bennett, M. J., Kovacs, A., . . Kelly, D. P. (2002). The cardiac phenotype induced by PPARalpha overexpression mimics that caused by diabetes mellitus. $J$ Clin Invest, 109(1), 121-130. doi: 10.1172/JCI14080

17-Garg, R., Rao, A. D., Baimas-George, M., Hurwitz, S., Foster, C., Shah, R. V., . . . Adler, G. K. (2015). Mineralocorticoid receptor blockade improves coronary microvascular function in individuals with type 2 diabetes. Diabetes, 64(1), 236-242. doi: $10.2337 / \mathrm{db} 14-0670$

18- Giacchetti, G., Sechi, L. A., Rilli, S., \& Carey, R. M. (2005). The reninangiotensin-aldosterone system, glucose metabolism and diabetes. Trends Endocrinol Metab, 16(3), 120-126. doi: 10.1016/j.tem.2005.02.003

19-Giacco, F., \& Brownlee, M. (2010). Oxidative stress and diabetic complications. Circ Res, 107(9), 1058-1070. doi: 10.1161/CIRCRESAHA.110.223545

20-Guo, C. A., \& Guo, S. (2017). Insulin receptor substrate signaling controls cardiac energy metabolism and heart failure. J Endocrinol, 233(3), R131R143. doi: 10.1530/JOE-16-0679

21-Gurusamy，N., Watanabe, K., Ma, M., Zhang, S., Muslin, A. J., Kodama, M., \& Aizawa, Y. (2004). Dominant negative 14-3-3 promotes cardiomyocyte apoptosis in early stage of type I diabetes mellitus through activation of JNK. Biochem Biophys Res Commun, 320(3), 773780. doi: 10.1016/j.bbrc.2004.06.023

22- Habets，D. D., Coumans, W. A., Voshol, P. J., den Boer, M. A., Febbraio, M., Bonen, A., ... Luiken, J. J. (2007). AMPK-mediated increase in myocardial long-chain fatty acid uptake critically depends on sarcolemmal CD36. Biochem Biophys Res Commun, 355(1), 204210. doi: 10.1016/j.bbrc.2007.01.141 
23- Holscher, M. E., Bode, C., \& Bugger, H. (2016). Diabetic Cardiomyopathy: Does the Type of Diabetes Matter? Int $J$ Mol Sci, 17(12). doi: 10.3390/ijms 17122136

24- Jia, G., DeMarco, V. G., \& Sowers, J. R. (2016). Insulin resistance and hyperinsulinaemia in diabetic cardiomyopathy. Nat Rev Endocrinol, 12(3), 144-153. doi: 10.1038/nrendo.2015.216

25- Jia, G., Habibi, J., Aroor, A. R., Hill, M. A., DeMarco, V. G., Lee, L. E., . . . Sowers, J. R. (2018). Enhanced endothelium epithelial sodium channel signaling prompts left ventricular diastolic dysfunction in obese female mice. Metabolism, 78, 69-79. doi:

10.1016/j.metabol.2017.08.008

26- Jia, G., Habibi, J., DeMarco, V. G., Martinez-Lemus, L. A., Ma, L., Whaley-Connell, A. T., . . Sowers, J. R. (2015). Endothelial Mineralocorticoid Receptor Deletion Prevents Diet-Induced Cardiac Diastolic Dysfunction in Females. Hypertension, 66(6), 1159-1167. doi: 10.1161/HYPERTENSIONAHA.115 .06015

27- Jones, S. P., \& Bolli, R. (2006). The ubiquitous role of nitric oxide in cardioprotection. J Mol Cell Cardiol, 40(1), 16-23. doi: 10.1016/j.yjmcc.2005.09.011

28- Jornayvaz, F. R., Birkenfeld, A. L., Jurczak, M. J., Kanda, S., Guigni, B. A., Jiang, D. C., . . . Shulman, G. I. (2011). Hepatic insulin resistance in mice with hepatic overexpression of diacylglycerol acyltransferase 2. Proc Natl Acad Sci U S A, 108(14), 57485752. doi: 10.1073/pnas.1103451108 29- Kanamori, H., Takemura, G., Goto, K., Tsujimoto, A., Mikami, A., Ogino, A., . . Minatoguchi, S. (2015). Autophagic adaptations in diabetic cardiomyopathy differ between type 1 and type 2 diabetes. Autophagy, 11(7), 1146-1160. doi: 10.1080/15548627.2015.1051295

30-Kanaporis, G., \& Blatter, L. A. (2017). Membrane potential determines calcium alternans through modulation of SR $\mathrm{Ca}(2+)$ load and Ltype $\mathrm{Ca}(2+)$ current. J Mol Cell Cardiol, 105, 49-58. doi: 10.1016/j.yjmcc.2017.02.004

31-Kannel, W. B., Hjortland, M., \& Castelli, W. P. (1974). Role of diabetes in congestive heart failure: the Framingham study. Am J Cardiol, 34(1), 29-34. doi: 10.1016/00029149(74)90089-7

32- Kim, J. A., Jang, H. J., MartinezLemus, L. A., \& Sowers, J. R. (2012). Activation of mTOR/p70S6 kinase by ANG II inhibits insulin-stimulated endothelial nitric oxide synthase and vasodilation. Am J Physiol Endocrinol Metab, 302(2), E201-208. doi: 10.1152/ajpendo.00497.2011

33- Kim, J. A., Wei, Y., \& Sowers, J. R. (2008). Role of mitochondrial dysfunction in insulin resistance. Circ Res, 102(4), 401-414. doi: 10.1161/CIRCRESAHA.107.165472

34- Lee, M., Gardin, J. M., Lynch, J. C., Smith, V. E., Tracy, R. P., Savage, P. J., . . . Ward, B. J. (1997). Diabetes

Delta University for Science and Technology

Coastal International Road, Mansoura, Gamasa City, Dakahlia, Egypt

E-mail: dusj@deltauniv.edu.eg

Journal homepage: www.deltauniv.edu.eg/dusj

page $\mid 105$ 
mellitus and echocardiographic left ventricular function in free-living elderly men and women: The Cardiovascular Health Study. Am Heart J, 133(1), 36-43. doi: 10.1016/s0002-8703(97)70245-x

35-Lee, S. J., Kang, J. G., Ryu, O. H., Kim, C. S., Ihm, S. H., Choi, M. G., . . . Kim, T. W. (2009). Effects of alpha-lipoic acid on transforming growth factor beta1-p38 mitogenactivated protein kinase-fibronectin pathway in diabetic nephropathy. Metabolism, 58(5), 616-623. doi: 10.1016/j.metabol.2008.12.006

36- Lee, T. I., Kao, Y. H., Chen, Y. C., Huang, J. H., Hsiao, F. C., \& Chen, Y. J. (2013). Peroxisome proliferatoractivated receptors modulate cardiac dysfunction in diabetic cardiomyopathy. Diabetes Res Clin Pract, 100(3), 330-339. doi: 10.1016/j.diabres.2013.01.008

37-Lee, T. W., Bai, K. J., Lee, T. I., Chao, T. F., Kao, Y. H., \& Chen, Y. J. (2017). PPARs modulate cardiac metabolism and mitochondrial function in diabetes. J Biomed Sci, 24(1), 5. doi: 10.1186/s12929-0160309-5

38-Lehrke, M., \& Marx, N. (2017). Diabetes Mellitus and Heart Failure. Am J Cardiol, 120(1S), S37-S47. doi: 10.1016/j.amjcard.2017.05.014

39- Lei, S., Li, H., Xu, J., Liu, Y., Gao, X., Wang, J., . . . Xia, Z. (2013). Hyperglycemia-induced protein kinase $\mathrm{C}$ beta2 activation induces diastolic cardiac dysfunction in diabetic rats by impairing caveolin-3 expression and Akt/eNOS signaling. Diabetes, 62(7), 2318-2328. doi: $10.2337 / \mathrm{db} 12-1391$

40- Leone, T. C., Weinheimer, C. J., \& Kelly, D. P. (1999). A critical role for the peroxisome proliferator-activated receptor alpha (PPARalpha) in the cellular fasting response: the PPARalpha-null mouse as a model of fatty acid oxidation disorders. Proc Natl Acad Sci U S A, 96(13), 74737478. doi: 10.1073/pnas.96.13.7473

41-Li, Z., Abdullah, C. S., \& Jin, Z. Q. (2014). Inhibition of PKC-theta preserves cardiac function and reduces fibrosis in streptozotocininduced diabetic cardiomyopathy. $\mathrm{Br}$ J Pharmacol, 171(11), 2913-2924. doi: 10.1111/bph.12621

42-Lind, M., Bounias, I., Olsson, M., Gudbjornsdottir, S., Svensson, A. M., \& Rosengren, A. (2011). Glycaemic control and incidence of heart failure in 20,985 patients with type 1 diabetes: an observational study. Lancet, 378(9786), 140-146. doi: 10.1016/S0140-6736(11)60471-6

43-Liu, F., Song, R., Feng, Y., Guo, J., Chen, Y., Zhang, Y., . . X Xiao, R. P. (2015). Upregulation of MG53 induces diabetic cardiomyopathy through transcriptional activation of peroxisome proliferation-activated receptor alpha. Circulation, 131(9), 795-804. doi: 10.1161/CIRCULATIONAHA.114.0 12285

44- Liu, W., Chen, P., Deng, J., Lv, J., \& Liu, J. (2017). Resveratrol and polydatin as modulators of $\mathrm{Ca}(2+)$

Delta University for Science and Technology

Coastal International Road, Mansoura, Gamasa City, Dakahlia, Egypt

E-mail: dusj@deltauniv.edu.eg

Journal homepage: www.deltauniv.edu.eg/dusj

page $\mid 106$ 
mobilization in the cardiovascular system. Ann N Y Acad Sci, 1403(1), 82-91. doi: 10.1111/nyas.13386

45-Lytvyn, Y., Bjornstad, P., Udell, J. A., Lovshin, J. A., \& Cherney, D. Z. I. (2017). Sodium Glucose Cotransporter-2 Inhibition in Heart Failure: Potential Mechanisms, Clinical Applications, and Summary of Clinical Trials. Circulation, 136(17), 1643-1658. doi: 10.1161/CIRCULATIONAHA.117.0 30012

46- Malhotra, A., \& Sanghi, V. (1997). Regulation of contractile proteins in diabetic heart. Cardiovasc Res, 34(1), 34-40. doi: 10.1016/s00086363(97)00059-х

47-Mariappan, N., Elks, C. M., Sriramula, S., Guggilam, A., Liu, Z., Borkhsenious, O., \& Francis, J. (2010). NF-kappaB-induced oxidative stress contributes to mitochondrial and cardiac dysfunction in type II diabetes. Cardiovasc Res, 85(3), 473-483. doi: 10.1093/cvr/cvp305

48- Marso, S. P., Bain, S. C., Consoli, A., Eliaschewitz, F. G., Jodar, E., Leiter, L. A., . . Investigators, S.-. (2016). Semaglutide and Cardiovascular Outcomes in Patients with Type 2 Diabetes. N Engl J Med, 375(19), 1834-1844. doi: 10.1056/NEJMoa1607141

49- Marso, S. P., Daniels, G. H., BrownFrandsen, K., Kristensen, P., Mann, J. F., Nauck, M. A., . . Investigators, L. T. (2016). Liraglutide and Cardiovascular Outcomes in Type 2
Diabetes. N Engl J Med, 375(4), 311322. doi: 10.1056/NEJMoa1603827

50-Miller，J. A. (1999). Impact of hyperglycemia on the renin angiotensin system in early human type 1 diabetes mellitus. J Am Soc Nephrol, 10(8), 1778-1785.

51- Miller, J. A., Floras, J. S., Zinman, B., Skorecki, K. L., \& Logan, A. G. (1996). Effect of hyperglycaemia on arterial pressure, plasma renin activity and renal function in early diabetes. Clin Sci (Lond), 90(3), 189195. doi: 10.1042/cs0900189

52-Murdoch, C. E., Chaubey, S., Zeng, L., Yu, B., Ivetic, A., Walker, S. J., . . . Shah, A. M. (2014). Endothelial NADPH oxidase-2 promotes interstitial cardiac fibrosis and diastolic dysfunction through proinflammatory effects and endothelial-mesenchymal transition. J Am Coll Cardiol, 63(24), 27342741.

doi: 10.1016/j.jacc.2014.02.572

53-Mytas，D. Z., Stougiannos，P. N., Zairis, M. N., Foussas, S. G., Pyrgakis, V. N., \& Kyriazis, I. A. (2009). Diabetic myocardial disease: pathophysiology, early diagnosis and therapeutic options. $J$ Diabetes Complications, 23(4), 273-282. doi: 10.1016/j.jdiacomp.2007.12.005

54- Niture, S. K., Khatri, R., \& Jaiswal, A. K. (2014). Regulation of Nrf2-an update. Free Radic Biol Med, 66, 3644.

doi: 10.1016/j.freeradbiomed.2013.02.00 8

Delta University for Science and Technology

Coastal International Road, Mansoura, Gamasa City, Dakahlia, Egypt

E-mail: dusj@deltauniv.edu.eg

Journal homepage: www.deltauniv.edu.eg/dusj

page |107 
55- Pal, P. B., Sonowal, H., Shukla, K., Srivastava, S. K., \& Ramana, K. V. (2017). Aldose Reductase Mediates NLRP3 Inflammasome-Initiated Innate Immune Response in Hyperglycemia-Induced Thp1 Monocytes and Male Mice. Endocrinology, 158(10), 3661-3675. doi: 10.1210/en.2017-00294

56- Passino, C., Barison, A., Vergaro, G., Gabutti, A., Borrelli, C., Emdin, M., \& Clerico, A. (2015). Markers of fibrosis, inflammation, and remodeling pathways in heart failure. Clin Chim Acta, 443, 29-38. doi: 10.1016/j.cca.2014.09.006

57-Pham, D., Albuquerque Rocha, N., McGuire, D. K., \& Neeland, I. J. (2017). Impact of empagliflozin in patients with diabetes and heart failure. Trends Cardiovasc Med, 27(2), 144-151. doi: 10.1016/j.tcm.2016.07.008

58- Pollack, P. S., Malhotra, A., Fein, F. S., \& Scheuer, J. (1986). Effects of diabetes on cardiac contractile proteins in rabbits and reversal with insulin. Am J Physiol, 251(2 Pt 2), H448-454. doi: 10.1152/ajpheart.1986.251.2.H448

59- Qi, Y., Xu, Z., Zhu, Q., Thomas, C., Kumar, R., Feng, H., . . . Guo, S. (2013). Myocardial loss of IRS1 and IRS2 causes heart failure and is controlled by p38alpha MAPK during insulin resistance. Diabetes, 62(11), 3887-3900. doi: 10.2337/db13-0095

60- Qi, Y., Zhu, Q., Zhang, K., Thomas, C., Wu, Y., Kumar, R., . . . Guo, S. (2015). Activation of Foxo1 by insulin resistance promotes cardiac dysfunction and beta-myosin heavy chain gene expression. Circ Heart Fail, 8(1), 198-208. doi: 10.1161/CIRCHEARTFAILURE. 11 4.001457

61-Razeghi, P., Young, M. E., Cockrill, T. C., Frazier, O. H., \& Taegtmeyer, H. (2002). Downregulation of myocardial myocyte enhancer factor $2 \mathrm{C}$ and myocyte enhancer factor $2 \mathrm{C}$ regulated gene expression in diabetic patients with nonischemic heart failure. Circulation, 106(4), 407-411. doi:

10.1161/01.cir.0000026392.80723.d

$\mathrm{C}$

62- Rosenkranz, A. C., Hood, S. G., Woods, R. L., Dusting, G. J., \& Ritchie, R. H. (2003). B-type natriuretic peptide prevents acute hypertrophic responses in the diabetic rat heart: importance of cyclic GMP. Diabetes, 52(9), 2389-2395. doi: 10.2337/diabetes.52.9.2389

63-Ryden, L., Armstrong, P. W., Cleland, J. G., Horowitz, J. D., Massie, B. M., Packer, M., \& PooleWilson, P. A. (2000). Efficacy and safety of high-dose lisinopril in chronic heart failure patients at high cardiovascular risk, including those with diabetes mellitus. Results from the ATLAS trial. Eur Heart J, 21(23), 1967-1978. doi: 10.1053/euhj.2000.2311

64-Sabolic, I., Vrhovac, I., Eror, D. B., Gerasimova, M., Rose, M., Breljak, D., . . . Koepsell, H. (2012). Expression of Na+-D-glucose

Delta University for Science and Technology

Coastal International Road, Mansoura, Gamasa City, Dakahlia, Egypt

E-mail: dusj@deltauniv.edu.eg

Journal homepage: www.deltauniv.edu.eg/dusj

page $\mid 108$ 
cotransporter SGLT2 in rodents is kidney-specific and exhibits sex and species differences. Am J Physiol Cell Physiol, 302(8), C1174-1188. doi: 10.1152/ajpcell.00450.2011

65-Samuel, V. T., \& Shulman, G. I. (2016). The pathogenesis of insulin resistance: integrating signaling pathways and substrate flux. $J$ Clin Invest, 126(1), 12-22. doi: 10.1172/JCI77812

66- Sandesara, P. B., O'Neal, W. T., Kelli, H. M., Samman-Tahhan, A., Hammadah, M., Quyyumi, A. A., \& Sperling, L. S. (2018). The Prognostic Significance of Diabetes and Microvascular Complications in Patients With Heart Failure With Preserved Ejection Fraction. Diabetes Care, 41(1), 150-155. doi: $10.2337 / \mathrm{dc} 17-0755$

67-Shome, J. S., Perera, D., Plein, S., \& Chiribiri, A. (2017). Current perspectives in coronary microvascular dysfunction. Microcirculation, 24(1). doi: 10.1111/micc. 12340

68-Song, R., Peng, W., Zhang, Y., Lv, F., Wu, H. K., Guo, J., . . . Xiao, R. P. (2013). Central role of E3 ubiquitin ligase MG53 in insulin resistance and metabolic disorders. Nature, 494(7437), 375-379. doi: 10.1038/nature11834

69- Strniskova, M., Barancik, M., Neckar, J., \& Ravingerova, T. (2003). Mitogen-activated protein kinases in the acute diabetic myocardium. Mol Cell Biochem, 249(1-2), 59-65.
70- Sundgren, N. C., Giraud, G. D., Schultz, J. M., Lasarev, M. R., Stork, P. J., \& Thornburg, K. L. (2003). Extracellular signal-regulated kinase and phosphoinositol-3 kinase mediate IGF-1 induced proliferation of fetal sheep cardiomyocytes. Am J Physiol Regul Integr Comp Physiol, 285(6), R1481-1489. doi: 10.1152/ajpregu.00232.2003

71- Talukder, M. A., Kalyanasundaram, A., Zuo, L., Velayutham, M., Nishijima, Y., Periasamy, M., \& Zweier, J. L. (2008). Is reduced SERCA2a expression detrimental or beneficial to postischemic cardiac function and injury? Evidence from heterozygous SERCA2a knockout mice. Am $J$ Physiol Heart Circ Physiol, 294(3), H1426-1434. doi: 10.1152/ajpheart.01016.2007

72- Tan, Y., Ichikawa, T., Li, J., Si, Q., Yang, H., Chen, X., . . Cui, T. (2011). Diabetic downregulation of Nrf2 activity via ERK contributes to oxidative stress-induced insulin resistance in cardiac cells in vitro and in vivo. Diabetes, 60(2), 625-633. doi: $10.2337 / \mathrm{db} 10-1164$

73- Tate, M., Deo, M., Cao, A. H., Hood, S. G., Huynh, K., Kiriazis, H., . . . Ritchie, R. H. (2017). Insulin replacement limits progression of diabetic cardiomyopathy in the lowdose streptozotocin-induced diabetic rat. Diab Vasc Dis Res, 14(5), 423433.

doi:

$10.1177 / 1479164117710390$

74- Teshima, Y., Takahashi, N., Nishio, S., Saito, S., Kondo, H., Fukui, A., . . 
- Saikawa, T. (2014). Production of reactive oxygen species in the diabetic heart. Roles of mitochondria and NADPH oxidase. Circ J, 78(2), 300-306. doi: 10.1253/circj.cj-131187

75- Thrainsdottir, I. S., Aspelund, T., Thorgeirsson, G., Gudnason, V., Hardarson, T., Malmberg, K., . . . Ryden, L. (2005). The association between glucose abnormalities and heart failure in the population-based Reykjavik study. Diabetes Care, 28(3), 612-616. doi: 10.2337/diacare.28.3.612

76- Uchimura, K., Hayata, M., Mizumoto, T., Miyasato, Y., Kakizoe, Y., Morinaga, J., . . . Kitamura, K. (2014). The serine protease prostasin regulates hepatic insulin sensitivity by modulating TLR4 signalling. Nat Commun, 5, 3428. doi: 10.1038/ncomms4428

77- Vincent, M. A., Clerk, L. H., Lindner, J. R., Klibanov, A. L., Clark, M. G., Rattigan, S., \& Barrett, E. J. (2004). Microvascular recruitment is an early insulin effect that regulates skeletal muscle glucose uptake in vivo. Diabetes, 53(6), 1418-1423. doi: 10.2337/diabetes.53.6.1418

78- Vincent, M. A., Clerk, L. H., Lindner, J. R., Price, W. J., Jahn, L. A., LeongPoi, H., \& Barrett, E. J. (2006). Mixed meal and light exercise each recruit muscle capillaries in healthy humans. Am J Physiol Endocrinol Metab, 290(6), E1191-1197. doi: 10.1152/ajpendo.00497.2005
79- Vollus, G. C., Bradley, E. A., Roberts, M. K., Newman, J. M., Richards, S. M., Rattigan, S., . . . Clark, M. G. (2007). Graded occlusion of perfused rat muscle vasculature decreases insulin action. Clin Sci (Lond), 112(8), 457-466. doi: 10.1042/CS20060311

80- von Lewinski, D., Rainer, P. P., Gasser, R., Huber, M. S., Khafaga, M., Wilhelm, B., . . . Pieske, B. (2010). Glucose-transportermediated positive inotropic effects in human myocardium of diabetic and nondiabetic patients. Metabolism, 59(7), 1020-1028. doi: 10.1016/j.metabol.2009.10.025

81- Wakasaki, H., Koya, D., Schoen, F. J., Jirousek, M. R., Ways, D. K., Hoit, B. D., . . . King, G. L. (1997). Targeted overexpression of protein kinase $\mathrm{C}$ beta2 isoform in myocardium causes cardiomyopathy. Proc Natl Acad Sci U S A, 94(17), 9320-9325.

doi:

10.1073/pnas.94.17.9320

82- Wang, J., Song, Y., Wang, Q., Kralik, P. M., \& Epstein, P. N. (2006). Causes and characteristics of diabetic cardiomyopathy. Rev Diabet Stud, 3(3), 108-117. doi: 10.1900/RDS.2006.3.108

83-Wang, Y., Zhou, S., Sun, W., McClung, K., Pan, Y., Liang, G., . . . Cai, L. (2014). Inhibition of JNK by novel curcumin analog C66 prevents diabetic cardiomyopathy with a preservation of cardiac metallothionein expression. Am $J$ Physiol Endocrinol Metab, 306(11), 
E1239-1247.

doi:

10.1152/ajpendo.00629.2013

84- Westermeier, F., Riquelme, J. A., Pavez, M., Garrido, V., Diaz, A., Verdejo, H. E., . . . Lavandero, S. (2016). New Molecular Insights of Insulin in Diabetic Cardiomyopathy. Front Physiol, 7, 125. doi: 10.3389/fphys.2016.00125

85- Widyantoro, B., Emoto, N., Nakayama, K., Anggrahini, D. W., Adiarto, S., Iwasa, N., . . . Hirata, K. (2010). Endothelial cell-derived endothelin-1 promotes cardiac fibrosis in diabetic hearts through stimulation of endothelial-tomesenchymal transition. Circulation, 121(22), 2407-2418. doi: 10.1161/CIRCULATIONAHA.110.9 38217

86- Xie, Z., Lau, K., Eby, B., Lozano, P., He, C., Pennington, B., . . . Zou, M. H. (2011). Improvement of cardiac functions by chronic metformin treatment is associated with enhanced cardiac autophagy in diabetic OVE26 mice. Diabetes, 60(6), 1770-1778. doi: $10.2337 / \mathrm{db} 10-0351$

87-Xu, Y. Z., Zhang, X., Wang, L., Zhang, F., Qiu, Q., Liu, M. L., . . . Wu, X. L. (2013). An increased circulating angiotensin II concentration is associated with hypoadiponectinemia and postprandial hyperglycemia in men with nonalcoholic fatty liver disease. Intern Med, 52(8), 855-861. doi: 10.2169/internalmedicine.52.8839

88- Yang, J., Park, Y., Zhang, H., Xu, X., Laine, G. A., Dellsperger, K. C., \&
Zhang, C. (2009). Feed-forward signaling of TNF-alpha and NFkappaB via IKK-beta pathway contributes to insulin resistance and coronary arteriolar dysfunction in type 2 diabetic mice. Am J Physiol Heart Circ Physiol, 296(6), H18501858.

doi:

10.1152/ajpheart.01199.2008

89- Yang, L., Zhao, D., Ren, J., \& Yang, J. (2015). Endoplasmic reticulum stress and protein quality control in diabetic cardiomyopathy. Biochim Biophys Acta, 1852(2), 209-218. doi: 10.1016/j.bbadis.2014.05.006

90- Ye, G., Metreveli, N. S., Donthi, R. V., Xia, S., Xu, M., Carlson, E. C., \& Epstein, P. N. (2004). Catalase protects cardiomyocyte function in models of type 1 and type 2 diabetes. Diabetes, 53(5), 1336-1343. doi: 10.2337/diabetes.53.5.1336

91-Young, M. E., Patil, S., Ying, J., Depre, C., Ahuja, H. S., Shipley, G. L., . . . Taegtmeyer, H. (2001). Uncoupling protein 3 transcription is regulated by peroxisome proliferatoractivated receptor (alpha) in the adult rodent heart. FASEB J, 15(3), 833845. doi: 10.1096/fj.00-0351com

92-Zhang, H., Shi, X., Hampong, M., Blanis, L., \& Pelech, S. (2001). Stress-induced inhibition of ERK1 and ERK2 by direct interaction with p38 MAP kinase. J Biol Chem, 276(10), 6905-6908. doi: 10.1074/jbc.C000917200

93-Zhang, Z., Wang, S., Zhou, S., Yan, X., Wang, Y., Chen, J., . . . Cai, L. (2014). Sulforaphane prevents the

Delta University for Science and Technology

Coastal International Road, Mansoura, Gamasa City, Dakahlia, Egypt

E-mail: dusj@deltauniv.edu.eg

Journal homepage: www.deltauniv.edu.eg/dusj

page $\mid 111$ 
development of cardiomyopathy in type 2 diabetic mice probably by reversing oxidative stress-induced inhibition of LKB1/AMPK pathway. J Mol Cell Cardiol, 77, 42-52. doi: 10.1016/j.yjmcc.2014.09.022

94-Zhou, Y. T., Grayburn, P., Karim, A., Shimabukuro, M., Higa, M., Baetens, D., .. . Unger, R. H. (2000). Lipotoxic heart disease in obese rats: implications for human obesity. Proc Natl Acad Sci U S A, 97(4), 17841789. doi: 10.1073/pnas.97.4.1784

95-Zinman, B., Wanner, C., Lachin, J. M., Fitchett, D., Bluhmki, E., Hantel, S., . . Investigators, E.-R. O. (2015). Empagliflozin, Cardiovascular Outcomes, and Mortality in Type 2 Diabetes. N Engl J Med, 373(22), 2117-2128. doi: 10.1056/NEJMoa1504720

96-Zou, M. H., \& Xie, Z. (2013). Regulation of interplay between autophagy and apoptosis in the diabetic heart: new role of AMPK. Autophagy, 9(4), 624-625. doi: 10.4161/auto.23577 